\title{
Reflection and Construction of Mental Health Education Model in Colleges and Universities from the Perspective of Positive Psychology
}

\author{
Miao Li \\ School of Education, Tianjin University, Tianjin, China, 300350 \\ limiao1994@tju.edu.cn
}

\begin{abstract}
Positive psychology studies psychology from a unique perspective, focusing on the positive qualities and strengths that human beings possess, shaping sound personality, and advocating the positive interpretation of problems. This article starts with discussion of the application value of positive psychology in college mental health education from the perspective of positive psychology culture, then analyzes the current situation of college mental health education. The shortcomings of the current college mental health education model mainly include three aspects: misunderstanding in the connotation of mental health education, service objects deviation during mental health education, single and old mode in mental health education. Meanwhile, this paper proposes some developmental suggestions: improve teaching content and change the way of teaching; use online media to broaden work channels; create a positive campus environment; build an integrated social support system.
\end{abstract}

Keywords-Positive Psychology; Mental Health Education; Model Reflection; Model Construction

\section{INTRODUCTION}

In the 1990 s, colleges and universities in our country began to pay attention to college students' mental health education. Most colleges and universities set up a mental health education center, equipped with full-time and part-time teachers to implement the improvement of mental health education level, this measure has achieved certain results. Researchers have conducted cross-sectional historical studies on the changes in the mental health of university students and found that the overall level of mental health of Chinese college students has gradually increased from 1986 to 2010 [1]. However, problems such as interpersonal relationships, academic pressures, social adjustments, and employment prospects have made college students susceptible to various types of mental and behavioral problems, and the severity has increased in order [2]. Some researchers also found that from 2004 to 2013, college students' extroversion, openness, conscientiousness, and agreeableness were improved, but neuroticism became worse [3]. Under such circumstances, how to change the current mental health education model and reduce the sudden incidents caused by students' mental problems and then enhance the mental health of college students are more important. At the end of the 20th century, American psychologist Martin E.P. Seligman put forward the concept of positive psychology, advocated psychology should be converted into a new type of science to study the advantages of human beings, we must study the positive quality of human beings, pay attention to the survival and development of human beings, and realize the unity of humanistic care and scientific spirit. [4]. This concept provides a brand-new perspective for mental health education in colleges and universities.

\section{The Basic CONCEPTS AND VALUes of Positive PSYCHOLOGY}

Positive psychology is a science that studies human potential and virtue. Its research field mainly involves three aspects: First, the subjective level of individual experience, including happiness, hope, satisfaction, and happiness; The research of positive psychology of individual growth includes optimism, wisdom, courage, and tolerance; Third, the study of civic virtues at the group level includes good teams, happy families, and harmonious communities. In essence, positive psychology is not the opposition content of the traditional psychology but complements it. This kind of supplement makes psychology research no longer confined to negative content such as anxiety, depression, and so on, expands the field of psychology research, makes psychology more complete, and allows more people to benefit from psychology.

Positive psychology look at individual quality from a positive view, and believes that everyone has intrinsic potential for development and focuses on the formation of positive personality and positive qualities. Positive quality is a constructive force that plays an important role in personal development and social progress. Starting from positive psychology, mental health education can expand the connotation o mental health education in colleges and universities, enrich the content of mental health education, make it better serve students, and make contributions to society. 


\section{REFLECTIONS ON MENTAL HEALTH MOdEL IN COLLEGES AND UNIVERSITIES}

\section{A. Misunderstandings in the connotation of mental health education}

In 2001, WHO defined the concept of mental health. It states that "mental health is a state of health or happiness in which individuals achieve self, be able to cope with daily stress, work productively, and can have the ability to contribute to their communities [5]. With the development and progress of society, some scholars have supplemented and improved the standards of mental health, and summarized them mainly as emotional stability, accept yourself, harmonious interpersonal relationships, coordinated and unified roles and functions, selflearning and independent living, and adaptation to the environment and deal with setbacks. It can be seen that mental health does not only mean that there is no mental illness [6]. Positive psychology advocates that mental health education should cultivate positive psychological qualities of students, mobilize subjective initiative, guide them to establish confidence in face of setbacks, enhance sense of hope, and then increase life satisfaction and subjective well-being.

At the present stage, mental health education in colleges and universities is mostly based on crisis intervention and problem solving. It focuses on those few students with emotional distress, maladaptation, and misalignment, and believes that mental health education means students don't have psychological problems. Under the guidance of this model, colleges and universities mainly study "unhealthy" or abnormal state such as suicide, anxiety, depression, compel, etc. rather than health status.

\section{B. Mental health education's service objects are biased}

Under the guidance of the traditional "negative" psychology, the mental health education in colleges and universities focuses on the students who have psychological distress, and emphasizes the correction of psychological diseases and the resolution of psychological problems. Psychological teachers in colleges and universities mainly serve students who have come to seek help and those who have not taken the initiative to seek help but have experienced major psychological crisis events; or they have conducted some psychological screening activities, posted posters and distributed information. The prevention of mental health education is greater than intervention, and this work orientation based on problems cannot fundamentally solve the problem. In the long run, the student union believes that only when there is a psychological problem will the teacher's attention be given, and even the student will be negatively concerned. Over time, the problem really arises. This not only go against the original intention of the mental health work, but also makes the psychological counseling stigmatization and weakens the effectiveness of mental health education work.

\section{The mental health education work style is single and old}

At present, the mental health education in colleges and universities is mainly carried out in three aspects: First, public elective courses or required courses for mental health education are offered. However, there is no uniform teaching material and there is no uniform standard for such courses. Teachers' lectures are conducted according to their own research directions. Content is confusing and in varying depths. Second, psychological consultation services are provided for students who think they need psychological counseling. But, the allocation of teachers in many colleges and universities is still insufficient to meet the needs of the entire students; Third, when students have serious psychological problems do crisis intervention, in real life, this is the greatest significance of mental health education in many schools. These measures are convenient ways for schools to carry out mental health education work. However, in the implementation process, problem solving is the goal. The form is old and single, and the effect is not good.

\section{Constructions of Diversified Mental Health EDUCATION MODEL UNDER THE GUIDANCE OF POSITIVE PSYCHOLOGY}

\section{A. Improve teaching content and change the way of teaching}

The value orientation of positive psychology emphasizes the discovery of individual's positive quality and development potential, which injects fresh power into the mental health curriculum of colleges and universities. The content of mental health curriculum should guide students to focus on interest, optimism and self-confidence. It is no longer focused on the prevention of mental illness and the solution of psychological confusion, and provides a variety of methods to enhance students' subjective well-being. In the teaching process, knowledge, experience and methods should be combined to focus on cultivating students' practical ability. And then build a complete mental health education curriculum system, so that students in the classroom can enhance their own quality and improve their ability to adapt on the basis of learn mental health knowledge.

Positive psychology believes that everyone is in the process of growth and development. There is no difference between teachers and students. Teachers need to keep pace with the times and adopt a variety of teaching patterns, such as MOOC, flipping classrooms, topic discussions, and student sharing sessions, rather than a single teacher teaching and student acceptance model. Multi-mode teaching inspire students' initiative fully, pay attention to the students' strengths and strengths, view each student with appreciation, and fully stimulate students' development potential. 


\section{B. Use online media to broaden work channels}

In the era of Internet+, the speed of Internet communication has broken the limitations of traditional media. College students are young and young, active in thinking, and easy to accept new ideas and new things. They have become the most active users of new media. Schools should seize the opportunity to make full use of new media, carefully prepare educational content, and apply mental health education work to all aspects of student life. In the online media, establish a column of mental health education knowledge, such as "each day to learn psychology," etc., to disseminate mental health knowledge in a subtle, sundry, silent way to shape the students' active psychological quality. The school's mental health education center must strengthen communication with the college and set up columns such as "Students' Style" and "My Self-confidence Road" in the media to fully develop the force of example, cultivate students' positive qualities, and improve their subjective well-being. In addition, colleges and universities must also combine the actual work of colleges and universities to help students learn reasonable attributions and do emotional management and stress relief.

\section{Create an positive campus environment}

Creating a positive campus culture atmosphere is an essential environmental condition for cultivating the positive psychological qualities of university students. Positive Psychology emphasizes participation and experience. Through diversified campus activities, students can not only enrich their self-experience, but also satisfy their make friends and selfdisplay needs.

First, organizing psychological drama matches to enrich students' self-experience. The cultivation of positive psychological qualities is not an overnight process, but a long process. Script selections, performances, and props preparation all require students to cooperate with each other. In this process, students can choose their own content to experience, satisfy curiosity, learn psychological knowledge, and promote psychological growth. Carry out psychological drama matches to increase the psychological experience of students through role-play. Each student will become the mentor of another student in the process of self-development. Mutual affirmation, praise and acceptance among students will promote common progress. In the face of difficulties and setbacks, teamwork together can improve students' ability to resist setbacks and allow students to learn mutual respect and encouragement.

Second, conduct group counseling activities to enhance student confidence. Self-confidence plays a significant role in the process of individual growth and is the cornerstone of success. It should be used as an entry point to cultivate students' positive qualities. In group activities, students are able to lay down their burdens, show their desires, and then find their own strengths and strengths and gain self-confidence, promote individual success. Success will make them more confident, and thus form a virtuous circle.

Third, carry out quality development activities to stimulate students' potential. Positive Psychology pays attention to the development of individual potential. The forms of quality development activities are novel and varied. Participating activities enable individuals to feel their strength and value. Colleges and universities shall improve the teachers and hardware equipment for quality development activities, expand their coverage, provide opportunities for more students to participate in quality development, allow them to play a collaborative spirit, exercise perseverance and enhance their anti-frustration capabilities.

\section{Build an integrated social support system}

Social support refers to help from others, including actual visible support (such as material assistance, etc.), as well as experience of social support (such as being understood, respected, etc.). A good social support system can relieve stress, bring positive emotional experiences and enhance social adaptability. Social support has a "bottomed-off" function that allows individuals to actively respond to difficulties and pressures, sharpen their will, exercise their abilities, and develop a sound personality.

It is generally considered that education is the task of the school, especially at the stage of higher education. However, the continuous interaction between family members is an important foundation and part of education. Therefore, the mental health education of college students is not only the task of the school, but also the role of the family. Family is the cradle of individual growth, and it is one of the most important environments for socialization. The school's mental health education should be linked with the family and make a good connection between home and school. Parents should start from the aspects of parent-child relationship, family structure and family education, strengthen communication among family members, and strive to create a family environment that is warm, harmonious, positive, trusting, respectful, and caring, and that enables college students to feel the love and support from family.

Everyone lives in society and is affected by it. College students are no exception. They feel the influence of social from time to time such as political unrest, environmental pollution, food safety issues, employment pressure and son on, all of which will reduce students' level of subjective well-being Therefore, we must reform the social security system, improve legal system, expand employment, reduce unemployment, encourage entrepreneurship, protect environment, and strive to create a harmonious, fair, orderly, open social environment in which to live. College students experience the warmth of society and enhance their happiness. 


\section{SUMMARY}

Positive psychology focuses on the cultivation of individual's positive psychological qualities and the development of their potential, cultivating individuals' adaptability to the environment, and finally achieving selfrealization. Mental health education in colleges and universities is an important part of the healthy growth of college students. We must look at problems from the perspective of development, change the current "negative" orientation, and better serve students. In addition, the healthy growth and development of college students are also inseparable from the warm family and harmonious society. The psychological health education center of colleges and universities must also integrate the school family society. The three parties combine to create respect, acceptance and full of care for college students. Growth Environment.

\section{REFERENCES}

[1] Ziqiang Xin, Mei Zhang, Lin He. Cross-history study on the changes of college students' mental health[J]. Acta Psychologica Sinica, 2012, 44(5) 664-679. (In Chinese)

[2] Watkins, D. C., Hunt, et al. Increased demand for mental health services on college campuses: Perspective from administrators [J]. Qualitative Social Work Research \& Practice, 2012, 11(3):1535-1538.

[3] Yuan Tian, Hua Ming, Silin Huang, et al. A cross-sectional study of the personality changes of Chinese college students from 2004 to 2013[J]. Psychological Development and Education, 2017, 33(1): 30-36. (In Chinese)

[4] Yuanjiang Miao, Jiayuan Yu. Positive Psychology: Ideas and Actions [J] Journal of Nanjing Normal University (Social Science Edition), 2003 , 48(2): 81-87. (In Chinese)

[5] Zhiping Yang, Huajun Peng, et al. Operational Guidelines for Positive Psychology Group Activities [M]. Beijing: Mechanical Industry Press, 2016. (In Chinese) 